Pecher, D., Zeelenberg, R., \& Raaijmakers, J. G. W. (1998). Does pizza prime coin? Perceptual priming in lexical decision and pronunciation. Journal of Memory and Language, 38, 401-418.

\title{
Does Pizza Prime Coin? Perceptual Priming in Lexical Decision and Pronunciation
}

\author{
DIANE PECHER, RENÉ ZEELENBERG, AND JEROEN G. W. RAAIJMAKERS \\ University of Amsterdam
}

\begin{abstract}
In six experiments we investigated priming for perceptually related word pairs (i.e., words that refer to objects with the same shape such as pizza-coin), trying to replicate earlier findings by Schreuder, Flores d'Arcais and Glazenborg (1984) while avoiding some of the methodological problems that were present in that study. Under standard conditions no perceptual priming was obtained. However, in all experiments priming for associated pairs was found. Only after activation tasks that focused on perceptual features was priming for perceptually related word pairs was found in pronunciation. Perceptual priming was also obtained in lexical decision after activation tasks, but only when strong associates were not presented in the experiment. The results show that priming for perceptually related word pairs is not a general finding.
\end{abstract}

A well known finding, often reported in the literature, is that a response to a word (e.g., bread) is faster and more accurate if the target word is presented in the context of a related word, the prime (e.g., butter), than if it is presented in the context of an unrelated prime (e.g., chair). This associative priming effect was first obtained by Meyer and Schvaneveldt (1971) and has been replicated many times in both pronunciation (Seidenberg, Waters, Sanders, \& Langer, 1984; Balota \& Lorch, 1986) and lexical decision (McNamara, 1992; Zeelenberg, Pecher, de Kok, \& Raaijmakers, in press). Most priming studies have used associatively related prime-target pairs. In the present study we investigated priming effects for prime-target pairs that refer to objects that share physical attributes (e.g., pizza and coin are both round and flat). Such a perceptual priming effect has been found by Schreuder, Flores d'Arcais and Glazenborg (1984; Flores d'Arcais, Schreuder, \& Glazenborg, 1985). Several researchers have argued that this finding provides evidence for the hypothesis that automatic semantic priming effects can be obtained for word pairs that are not associatively related. This contrasts with the claim made by Shelton and Martin (1992) that nonassociative semantic priming effects are not supported by automatic processes. However, the interpretation of the Schreuder et al. results is seriously complicated by their experimental procedures. In the present study we re-examined priming for perceptually related pairs using more common and better controlled procedures.

Associative priming effects are traditionally explained by spreading activation (Anderson, 1983; Collins \& Loftus, 1975; McNamara, 1992; but see Masson, 1995; 
Ratcliff \& McKoon, 1988). According to spreading activation theory, memory is represented by a network of concepts. The nodes representing related concepts are connected in the network. For example, the node representing bread is connected to the node representing butter. If the word bread is presented, the bread node will be activated. The activation then spreads out across the links to all nodes that are connected to the bread node. This process leads to activation of related nodes such as the butter node. If the word butter is then presented, the butter node is already somewhat activated, and less additional activation is needed to reach the threshold for responding.

An issue that has received much attention is the difference between associative priming and nonassociative semantic priming. Associative priming is priming for word pairs that are associated according to free association norms (e.g., sun-moon). It is often assumed that data from free association norms reflect the structure of the network (Balota \& Lorch, 1986; de Groot, 1983; McNamara, 1992). Nonassociative semantic priming is priming for 'semantic only' pairs (i.e., pairs that are semantically related but are not associated according to free association norms, e.g., sun-Venus). Semantic relatedness is usually defined by category membership (Lupker, 1984; Shelton \& Martin, 1992, but see Moss, Ostrin, Tyler, \& Marslen-Wilson, 1995, for a different view). A number of studies have found priming effects for semantic only word pairs (Fischler, 1977; Seidenberg et al., 1984; Lund, Burgess, and Atchley, 1995), but others have questioned the source of this priming effect (Lupker, 1984; Shelton and Martin, 1992). The main issue is whether nonassociative semantic priming effects are the result of automatic priming or of strategies. Two types of strategies that have been proposed to play a role in priming are expectancy generation and relatedness checking (Neely, 1991).

According to the expectancy generation account, participants generate expectancies about the target after reading the prime (Becker, 1980; Neely, 1977; Posner \& Snyder, 1975). The response to the target will be facilitated if the target matches the expectancy generated by the participant. However, if the target does not match the expectancy the response to the target will be inhibited. This strategy is assumed to be effective only at longer SOAs, when participants have enough time to generate expectancies (Neely, 1977, den Heyer, Briand \& Dannenbring, 1983). Usually the expectancy that is generated will be an associate of the prime. Therefore, it might seem that the influence of expectancy strategies on the occurrence of priming for pairs that are semantically related but not associated is minimal. However, if primes are often followed by semantically related words such as words from the same semantic category, an expectation may be generated not for a specific target, but for all members of a category (see Becker, 1980, for a detailed model of expectancy based strategies for associates and category members).

The second type of strategy, relatedness checking, can also explain nonassociative semantic priming effects. According to the relatedness checking account a relatedness check is made after recognition of both prime and target but before responding (Balota \& Lorch, 1986; de Groot, 1983; Seidenberg et al., 1984). If a relation between prime and target is discovered this necessarily means that the target is a word because a nonword cannot be semantically related to a word. This will facilitate responding to the target. If no relation between prime and target is found there will be a bias to respond 'nonword' and thus responses will be slower. Because participants will usually detect a relation even for semantic only pairs this strategy will result in a priming effect for pairs that are semantically related but not associated.

Shelton and Martin (1992) have argued that nonassociative semantic priming effects are due to strategies and that only priming for associated word pairs is supported by 
automatic processes. They argued that the nonassociative semantic priming effect that had previously been obtained in lexical decision by Fischler (1977) was the result of relatedness checking. In the lexical decision task that was used by Fischler a response had to be made to the word pair instead of to the target alone, and this paired presentation procedure may promote relatedness checking. Shelton and Martin studied priming in a single presentation procedure, in which participants respond to each stimulus in a long continuous sequence of stimuli. In this procedure the stimulus on the preceding presentation acts as a prime for the stimulus on the present presentation. This procedure is assumed to eliminate relatedness checking strategies because the 'pairing' is less salient (Shelton \& Martin, 1992, Experiment 1 and 2; McNamara \& Altarriba, 1988). Using this procedure Shelton and Martin observed priming for associates but not for semantic only pairs. They concluded that automatic priming occurs only for word pairs that are associatively related.

Further support for Shelton and Martin's claim comes from studies that show that nonassociative semantic priming effects are usually small or absent in pronunciation (Lupker, 1984; Seidenberg et al., 1984). In this task, relatedness checking strategies are assumed to play no role (Balota \& Lorch, 1986; de Groot, 1985; Seidenberg et al., 1984) because the required response is pronunciation of the target, and noticing a relation between prime and target does not provide information about what response should be given. The small effects that have sometimes been obtained can be attributed to strategic processes. In the Seidenberg et al. experiment and in two of Lupker's experiments the SOA between prime and target was $500 \mathrm{~ms}$ or longer and in the Seidenberg et al. study all targets were presented twice, once in the related and once in the unrelated condition. These procedures may have led to expectancy generation. In addition, according to Shelton and Martin, the priming effects for semantic only pairs found in these studies could be the result of mediating associates. For example, words that are members of the same category may both be associated to the category name. If the prime is activated, activation may spread to the mediating concept, and then from the mediating concept to the target. In studies that used mediated associations that have no obvious semantic relation (lion-stripes, which is mediated by tiger) priming has been found (Balota \& Lorch, 1986; McNamara \& Altarriba, 1988).

Thus, there is no strong evidence that automatic priming effects can be found for semantic only word pairs. In lexical decision priming for semantic only pairs can be explained by relatedness checking. The obtained priming effects for semantic only pairs in pronunciation might have been due to expectancy based strategies or to mediating associations. Thus, Shelton and Martin concluded that priming for semantic only word pairs is not supported by automatic processes.

One finding reported in the literature, however, poses problems for the above conclusion. Schreuder et al. (1984) found priming for 'perceptually related' word pairs, i.e., pairs of words that are related because they refer to objects with the same shape, such as pizza-coin ${ }^{1}$. This can be considered a particular type of semantic priming because the physical appearance of a word's referent is part of the semantic information stored about a word. Schreuder et al. differentiated between two types of semantic information, which they referred to as perceptual and conceptual information. A perceptual relation is a relation that is based on the physical attributes of the concept that the word refers to. For example, orange and ball are perceptually related because they have the same shape. A conceptual relation is defined by more abstract features of a word. For example, skipping rope and ball are conceptually related because they are both toys. In the Schreuder et al. study perceptual and conceptual relatedness were systematically varied, so that word pairs could 
be perceptually related (orange-ball), conceptually related (skipping rope-ball), both perceptually and conceptually related (balloon-ball), or unrelated (hoe-ball). Schreuder et al. obtained additive effects of conceptual and perceptual relatedness. Moreover, priming due to the perceptual relation between prime and target was obtained in both pronunciation and lexical decision. These effects were later replicated by Flores d'Arcais et al. (1985).

The finding of priming for perceptually related words is important because it contrasts with the above conclusion that no automatic priming effects are found for semantic only pairs. Priming effects for perceptually related word pairs are not easily explained by strategies, because the relation between these words is rather subtle. Priming for perceptually related pairs can also not be explained by mediating associations, because there are no mediating associations for these pairs. Therefore, several researchers have argued that these results provide evidence for automatic nonassociative semantic priming effects (Chiarello, Burgess, Richards \& Pollock, 1990; Moss et al., 1995; Neely, 1991; Shelton \& Martin, 1992; Williams, 1996). Because perceptually related word pairs do not have direct associations, a priming effect for perceptually related word pairs poses problems for the view that no automatic priming is found for semantic only word pairs.

However, many researchers (Moss et al., 1995; Shelton \& Martin, 1992; Williams, 1996) have pointed out methodological problems that complicate the interpretation of the results obtained by Schreuder et al. (1984). These methodological problems are problems with both the materials and the procedure. A first problem with the materials is that the primes in the unrelated condition came from a different set than the primes in the related condition. This means that the conditions differed not only in the type of relation between the prime and target but also in the identity of the primes. This introduces a confounding between materials and experimental conditions. A methodologically better way of creating unrelated word pairs would be to recombine prime-target pairs so that the pairs become unrelated. For the design used by Schreuder et al. in which two types of relatedness are systematically varied it may be quite difficult to use the same primes in all conditions, but then a better solution might be to have an unrelated recombined control condition for each type of relatedness condition. A second problematic aspect of the Schreuder et al. study is that some words were used both as prime and target, and that some primes were used twice (with different targets). For example, the word pijp (pipe) was used as a prime for steelpan (saucepan) and as a prime for saxofoon (saxophone).

Additional points concern the procedure that Schreuder et al. (1984) used. First, an SOA of $400 \mathrm{~ms}$ was used and the prime remained on the screen while the target was presented. The presentation of the prime and target together may promote the use of strategies, because attention is drawn to the relation between the prime and target (Shelton \& Martin, 1992; see also Williams, 1996). However, the lexical decision task is more sensitive to strategies than the pronunciation task and Schreuder et al. also obtained an effect in pronunciation. Second, each target was presented four times, each time with a different type of prime. This may also have promoted the use of strategies (Shelton \& Martin, 1992). Furthermore, the results may have been affected by target repetition. Third, if an incorrect response was made, the word pair was repeated later in the experiment. Because error rates may differ for different conditions, and repetition of a target affects reaction time, this procedure may influence priming effects. A final point concerns the response latencies that Schreuder et al. obtained. In lexical decision the mean response time for unrelated word pairs was $694 \mathrm{~ms}$, and in pronunciation the mean was $629 \mathrm{~ms}$. These response times are rather long, especially for targets that are presented four times in the experiment. 
These methodological problems considerably complicate the interpretation of the results obtained by Schreuder et al. (1984) and Flores d'Arcais et al. (1985). Nonetheless, the notion of perceptual relatedness is interesting, because it provides us with a type of semantic relatedness that is not immediately obvious and thus may be less sensitive to strategies. It is also unlikely that the perceptual only word pairs have mediating associates that can have caused the priming effect. A possible finding of perceptual priming would therefore provide evidence against the claim of Shelton and Martin that nonassociative semantic priming effects are the result of strategies or mediating associations. More generally, it can also provide us with information about the representation and retrieval of semantic knowledge. The spreading activation theory of Collins and Loftus (1975) assumes that there is a direct relationship between the strength of an association in the semantic network and production frequency in a free association task. Automatic priming effects should also be related to the strength of connections in the semantic network. This follows from the theory, because the production of a response in the free association task and the associative priming effect in lexical decision and pronunciation are both explained by the same spreading activation process. Therefore, spreading activation theories assume that free association norms predict for which word pairs automatic priming effects will be found (McKoon \& Ratcliff, 1992). Thus, a priming effect for word pairs that are not associated according to free association norms would pose a problem for spreading activation theories of semantic memory.

The aim of the present experiments was to investigate whether we could replicate the priming effects for perceptually related word pairs in lexical decision and pronunciation that were found by Schreuder et al. (1984). We performed a replication with procedures that are less problematic than those of the Schreuder et al. study. In our experiments primes and targets were presented consecutively with an SOA of $350 \mathrm{~ms}$. Since we were interested in automatic priming effects a shorter SOA might seem preferable. However, the use of a shorter SOA entails the risk that the prime is not fully encoded when the target appears. The priming effect might therefore be underestimated if a very short SOA is used. Following McNamara (1994) we chose a $350 \mathrm{~ms}$ SOA. The prime disappeared before the target appeared, so that prime and target were never presented together on the screen. Another important difference from the procedure used by Schreuder et al. was that we created the unrelated condition by recombining prime-target pairs. This ensured that any difference between the related and unrelated condition would be due to the relation between prime and target. Finally, a new set of 18 perceptually related word pairs was selected in order to maximize the power of the experiment and to see if a possible priming effect would generalize to other word pairs. A separate set of associates was used to assess the sensitivity of the procedure for priming effects.

The aim of Experiment 1 and 2 was to investigate whether we could replicate Schreuder et al.'s (1984) finding of priming for perceptually related word pairs. Perceptual priming can be considered a special form of nonassociative semantic priming. The present experiments therefore also provide data relevant to the claim of Shelton and Martin (1992) that nonassociative semantic priming effects are the result of strategies. In Experiment $1 \mathrm{a}$ lexical decision task was used. Experiment 2 investigated perceptual priming in a pronunciation task.

\section{EXPERIMENT 1}

\section{Method}


Participants. Thirty-four students of the University of Amsterdam participated in the experiment. They received course credit for their participation. No student participated in more than one of the present series.

Apparatus and Materials. A set of 60 word pairs was created. This set consisted of 36 perceptually related word pairs and 24 associatively related word pairs. To select the perceptually related word pairs a norming study was done. A separate group of 40 students rated the perceptual similarity of 48 perceptually related word pairs. Of these pairs 18 were taken from Schreuder et al. (the original set consisted of 20 word pairs, but after removal of words that appeared more than once, only 18 pairs remained) and 30 were newly constructed by the authors and one of their colleagues. A word pair was considered perceptually related if the objects to which the words of the pair refer overlap in physical attributes, such as pizza-coin (which are both round and flat). No word appeared more than once in the set. Unrelated word pairs were constructed by recombining words within the set. The 40 participants rated the perceptual similarity of the word's referents on a scale of 1 to 5. On the basis of these ratings we selected 18 of the newly created pairs with the highest ratings. The mean ratings are presented in Table 1 . The perceptual relatedness ratings for the newly created pairs were higher than those for the pairs taken from the Schreuder et al. study. Therefore, any failure to replicate the perceptual priming effect in the present study cannot be ascribed to our stimuli having weaker perceptual relations than the stimuli used by Schreuder et al.

The associatively related word pairs were selected from published word association norms (de Groot, 1980; Lauteslager, Schaap, \& Schievels, 1986; van der Made-van Bekkum, 1973; van Loon-Vervoorn \& van Bekkum, 1991). In the stimulus list word pairs were recombined so as to create unrelated word pairs. Two versions of the stimulus list were created in order to counterbalance the targets over conditions. In each version half of the pairs (18 of the perceptual pairs and 12 of the associate pairs) were unrelated and the other half were related. All words appeared only once on the list. Each participant saw only one version of the stimulus list.

An additional set of 40 word-word fillers and 100 word-nonword fillers was created. The word-word fillers consisted of unrelated word pairs. The nonwords were pronounceable letter strings that were permissable by the rules of Dutch orthography. No stimulus was presented more than once. Stimuli were presented on the screen of a Macintosh SE computer. 
Table 1. Mean Ratings for Perceptually Related word pairs.

Related Unrelated

\begin{tabular}{lll} 
Schreuder et al. pairs & 3.36 & 1.40 \\
New pairs & 3.73 & 1.29 \\
Selected new pairs & 4.05 & 1.29 \\
\hline
\end{tabular}

Procedure. A trial started with a warning signal that was displayed for $450 \mathrm{~ms}$. This was replaced by a blank screen for $50 \mathrm{~ms}$. Then the prime was displayed for $300 \mathrm{~ms}$, followed by a blank screen of $50 \mathrm{~ms}$, resulting in a SOA of $350 \mathrm{~ms}$. Then the target was displayed on the same location where the prime had appeared, until the participant made a response. After a $1000 \mathrm{~ms}$ interval the next trial started. Participants responded word by pushing a button marked 'yes' with their right hand, and nonword by pushing a button marked 'no' with their left hand. If an error was made the word 'FOUT' ('error') was presented. If a response exceeded the deadline of $1000 \mathrm{~ms}$ the word 'LANGZAAM' ('slow') was presented. Stimuli were presented in blocks of 100 trials. After every block there was a short break and feedback was given on the number of correct responses.

Participants were told that they would see two letter strings on the screen and were asked to decide as quickly and as accurately as possible on each trial whether the second letter string represented a word. They were instructed to read the first letter string (the prime) but to respond only to the second letter string (the target). The experiment started with 30 practice trials, followed by 200 experimental trials. At the end of the experiment participants were asked whether they had noticed anything about the type of relation between primes and targets.

Results

Only correct response times shorter than $1000 \mathrm{~ms}$ were included in the analyses. This resulted in exclusion of $1.2 \%$ of the reaction times because they were outliers. The mean reaction times and error rates of the conditions are presented in Table 2 . The $39 \mathrm{~ms}$ difference between the related and unrelated pairs in the associative condition was significant, $t(33)=4.95, p<.001$. In the perceptual condition there was no significant difference between the related and the unrelated pairs, $t(33)=0.03, p=.98 .^{2}$ For the error rates none of the differences was significant. None of the participants had noticed the perceptual relation of some of the word pairs, whereas most participants had noticed the relationship for associated word pairs. 
Table 2. Mean Response Times (in milliseconds) and Percentage Errors for Experiment 1 and 2.

$$
\begin{array}{ll}
\text { Associated pairs } & \text { Perceptual pairs } \\
\text { RT PE } & \text { RT PE }
\end{array}
$$

Exp. 1: Lexical Decision

$\begin{array}{lcccccc}\text { Related } & 494 & 1.2 & & 581 & 7.7 & \\ \text { Unrelated } & & 533 & 2.5 & & 581 & 7.4 \\ \text { Priming } & 39 & 1.3 & & 0 & -0.3 & \end{array}$

Exp. 2: Pronunciation

$\begin{array}{lcccccc}\text { Related } & 481 & 0.5 & & 515 & 0.8 & \\ \text { Unrelated } & & 496 & 0.5 & & 516 & 1.1 \\ \text { Priming } & 15 & 0.0 & & 1 & 0.3 & \end{array}$

\section{EXPERIMENT 2}

In Experiment 1 we found no priming effect for perceptually related word pairs in the lexical decision task. In the next experiment we again investigated priming effects for the perceptually related word pairs from Experiment 1, but instead of lexical decision we used pronunciation. Schreuder et al. (1984) found a rather small priming effect for perceptually related word pairs in lexical decision. They obtained a larger effect using a pronunciation task.

\section{Method}

Participants. Thirty-four students of the University of Amsterdam participated for course credit.

Procedure and Materials. From the set of stimuli used in Experiment 1 the nonwords and the word filler trials were removed. This resulted in a list of 60 word-word pairs, 24 in the associative condition and 36 in the perceptual condition. Unrelated word pairs were created as in previous experiments and different lists were created to ensure counterbalancing.

The presentation procedure was similar to that used in Experiment 1, with the exception that instead of a lexical decision task a pronunciation task was used. Participants were asked to read the target aloud as quickly and as accurately as possible. A voice key was used to measure the time between the onset of the target and the beginning of the response.

Results 
Reaction times for errors, voice key failures, or responses that were longer than $1000 \mathrm{~ms}$ were excluded from the analyses. This resulted in the removal of $2.1 \%$ of the reaction times because of voice key failures and removal of $0.2 \%$ of the reaction times because they were outliers. Table 2 gives the mean reaction times and error rates of all conditions in Experiment 2. The $15 \mathrm{~ms}$ difference between the related and unrelated word pairs in the associated condition was significant, $t(33)=4.69, p<.001$. The $1 \mathrm{~ms}$ difference between the perceptually related and unrelated word pairs was not significant, $t(33)=0.26, p=.80$. For the error rates none of the differences were significant. None of the participants had noticed the perceptual relation of some of the word pairs.

\section{DISCUSSION OF EXPERIMENTS 1 AND 2}

In Experiments 1 and 2 we investigated priming effects in lexical decision and pronunciation. Significant priming was obtained for associated word pairs, but no priming effect was obtained for word pairs that have a perceptual relation. The absence of a priming effect for the perceptually related word pairs was not due to a lack of sensitivity of our procedure, because there was significant priming for associates.

Schreuder et al. (1984) did obtain priming effects for perceptually related word pairs in pronunciation and lexical decision. A difference between our data and those of Schreuder et al. is that in our experiments responses were faster. Can this difference in response times have affected the priming effect for perceptually related word pairs? Williams (1996) compared several studies that investigated priming for semantic only word pairs. He listed the mean response times in the unrelated condition for each study, together with the priming effect that was obtained for semantic only word pairs in that study. There seemed to be a trend that studies with longer response times in the unrelated condition produce larger priming effects. According to Williams this might be explained by assuming that longer response times leave more room for top down processes. Priming would be the result of a top down spreading activation process. When it takes longer for bottom up processes that translate the stimulus into a response to complete, for example if targets are degraded, the effect of top down processes increases.

If this hypothesis is correct, priming for perceptually related pairs might be absent in our experiment because response latencies were about $100 \mathrm{~ms}$ shorter than in the experiments of Schreuder et al. (1984). However, Schreuder et al. (1984) have argued that perceptual information becomes available earlier in processing than conceptual information. According to them, priming for perceptually related pairs reaches its maximum effectiveness earlier than priming for conceptually related pairs. In order to test this hypothesis, Flores d'Arcais et al. (1985) investigated the effect of response latency on the amount of priming. In lexical decision responses were speeded up by giving participants a short deadline for responding. In contrast, pronunciation latencies were slowed by degrading the target with a visual mask. Their results show that response latency did affect the amount of priming for conceptually related words but did not affect the amount of priming for perceptually related word pairs. Therefore, it is unlikely that differences in response latencies can explain the difference between our results and those of Schreuder et al.

Thus, contrary to Schreuder et al. (1984) and Flores d'Arcais et al. (1985), we did not obtain priming for perceptually related word pairs. In the next two experiments we further investigated priming effects for perceptually related word pairs. Priming for such word pairs might be obtained if participants are induced to process the perceptual properties of the words. If the perceptual features of words have already been activated 
prior to the priming task overlap in perceptual features might facilitate responding to the target. It has been suggested that the context in which a word has previously been presented affects what is retrieved about that word on a subsequent presentation (Barsalou, 1993). Thus, if the previous context has led to activation of perceptual features, these features will be more likely activated again on subsequent presentation. Perceptually related words then have some activated features in common and this overlap may result in a priming effect.

In order to activate perceptual information we presented the words individually in two activation tasks. In the first task participants were asked to judge whether the words referred to oblong objects. In the second task the same words were presented again, and participants were asked to judge whether the objects had a flat surface. After these activation tasks the priming task was presented. As in the previous experiments priming for perceptually related word pairs was investigated. Experiment 3 used lexical decision and Experiment 4 pronunciation.

\section{EXPERIMENT 3}

\section{Method}

Participants. Thirty students participated in the experiment. They received course credit or a small monetary fee for their participation.

Procedure and Materials. The same experimental stimuli were used as in Experiment 1 except that from the set of filler stimuli all word fillers and 40 word-nonword fillers were removed. This resulted in a list of 60 word-word and 60 word-nonword pairs.

The lexical decision procedure was identical to that used in Experiment 1. Before the lexical decision task we presented two other decision tasks. In these tasks all 72 words from the set of perceptually related word pairs were presented one at a time on the computer screen. In both tasks a decision had to be made about the perceptual features of the object to which the word referred. The first task was to decide whether the word referred to an oblong object. The second task was to decide whether the word referred to an object with a flat surface. For both decision tasks the stimulus set could be divided into two parts of about the same size for each response. Responses were made by pressing the 'yes' or 'no' buttons that were also used for the lexical decision task. The words remained on the screen until a response had been made, or until 5 seconds had elapsed. The instruction explained the kind of decision that was to be made, but did not mention speed or accuracy. These decision tasks were followed by the lexical decision task.

\section{Results}

Mean reaction times and error rates for the lexical decision task are given in Table 3. Only correct response times shorter than $1000 \mathrm{~ms}$ were included in the analyses. This resulted in exclusion of $0.9 \%$ of the reaction times. For the associative condition there was a significant $30 \mathrm{~ms}$ priming effect, $t(29)=3.97, p<.001$. Responses to the perceptually related word pairs were $5 \mathrm{~ms}$ slower than those to the unrelated control condition, but this difference was not significant, $t(29)=0.64, p=.53$. For the error rates the difference between the associated pairs and their unrelated control pairs was significant, $t(29)=2.54$, $p<.05$, but the difference between the perceptually related pairs and their unrelated control pairs was not, $t(29)=0.81, p=.42$. Six of the thirty participants had noticed the perceptual relation of some of the word pairs. 


\section{EXPERIMENT 4}

In Experiment 3 we again did not obtain priming for perceptually related word pairs in lexical decision. In Experiment 4 we used the same decision tasks to focus the participants' attention on perceptual properties. These tasks were followed by a pronunciation task in which we investigated priming effects for perceptually related word pairs.

\section{Method}

Participants. Thirty-four students participated in the experiment. They received course credit or a small monetary fee for their participation.

Procedure. The same set of stimuli as in Experiment 2 was used. Unrelated word pairs were created as in previous experiments and different lists were created to ensure counterbalancing. The procedure was similar to that used in Experiment 3, except that instead of a lexical decision task a pronunciation task was used. Participants were asked to name the target as quickly and as accurately as possible. A voice key was used to measure reaction times.

Results

Mean reaction times and error rates for the pronunciation task are given in Table 3. Reaction times for errors, voice key failures, or reaction times that were longer than 1000 ms were not included in the analyses. This resulted in the removal of $2.9 \%$ of the correct reaction times because of voice key failures, and $0.1 \%$ of the reaction times because they were outliers. For the associative condition there was a significant $27 \mathrm{~ms}$ priming effect, $t(33)=5.90, p<.001$. The 9 ms priming effect for the perceptually related word pairs also was significant, $t(33)=2.61, p<.05$. None of the effects in the error rates reached significance. Five of the 34 participants had noticed the perceptual relation of some of the word pairs. 
Table 3. Mean Response Times (in milliseconds) and Percentage Errors for Experiment 3 and 4.

$\begin{array}{ll}\text { Associated pairs } & \text { Perceptual pairs } \\ \text { RT PE } & \text { RT PE }\end{array}$

Exp. 3: Lexical Decision

$\begin{array}{lcccccc}\text { Related } & 517 & 1.7 & & 574 & 3.7 & \\ \text { Unrelated } & & 547 & 5.6 & & 569 & 4.8 \\ \text { Priming } & 30 & 3.9 & & -5 & 1.1 & \end{array}$

Exp. 4: Pronunciation

$\begin{array}{lcccccc}\text { Related } & 469 & 0.5 & & 500 & 1.0 & \\ \text { Unrelated } & & 496 & 1.5 & & 509 & 1.6 \\ \text { Priming } & 27 & 1.0 & & 9 & 0.6 & \end{array}$

\section{Discussion}

The results of Experiment 4 show that it is possible to obtain priming for perceptually related word pairs if those words are first presented in a task in which participants make judgments about the perceptual attributes of the referents of the words. This finding suggests that perceptual priming can be obtained if the perceptual properties of a word are processed prior to the priming task.

Before concluding that activation of perceptual features is necessary to obtain priming for perceptually related word pairs, an alternative explanation has to be excluded. There is a possibility that the priming effect for perceptually related word pairs is the result of word repetition alone. The activation of perceptual features of the words in not the only difference between Experiment 2 and Experiment 4. In Experiment 2 the words had not been presented at all prior to the pronunciation task. Therefore, the priming effect for perceptually related word pairs in Experiment 4 may somehow have been caused by repetition of the words. In the Schreuder et al. (1984) experiments targets were presented four times; so if the priming effect for perceptually related word pairs is the result of word repetition, this would explain the difference between their results and ours. In Experiment 5 this possibility was investigated by presenting the words prior to the pronunciation task, but unlike in Experiments 3 and 4, participants were only asked to read the words aloud.

\section{EXPERIMENT 5}

\section{Method}

Participants. Thirty-two students participated in the experiment. They received course credit for their participation. None of them had taken part in any of the previous experiments. 
Procedure. The stimuli and procedure were the same as in Experiment 4, with the exception that instead of the activation tasks, all words from the set of perceptually related word pairs were presented on the computer screen and participants were instructed to read each word aloud. The order of the words was randomized, and each word was presented twice (as it was in Experiments 3 and 4). To make presentation of the words as similar as possible to that of the activation tasks of Experiments 3 and 4, the words were presented for $1250 \mathrm{~ms}$ each, because this was close to the mean decision times (and thus the mean presentation times) in the activation tasks of the previous experiments.

Results

Mean reaction times and error rates are given in Table 4. Reaction times for errors, voice key failures, or reaction times that were longer than $1000 \mathrm{~ms}$ were not included in the analyses. This resulted in the removal of $1.0 \%$ of the reaction times because of voice key failures, and $0.1 \%$ of the reaction times because they were outliers. For the associative condition there was a significant $20 \mathrm{~ms}$ priming effect, $t(31)=5.38, p<.001$. The $1 \mathrm{~ms}$ priming effect for the perceptually related word pairs was not significant, $t(31)=0.11, p=$ 92. None of the effects in the error rates reached significance. None of the 32 participants had noticed the perceptual relation of some of the word pairs.

Table 4. Mean Response Times (in milliseconds) and Percentage Errors for Experiment 5.

$\begin{array}{ll}\text { Associated pairs } & \text { Perceptual pairs } \\ \text { RT PE } & \text { RT PE }\end{array}$

Exp. 5: Pronunciation

$\begin{array}{lclcrll}\text { Related } & 474 & 0.3 & & 486 & 1.0 & \\ \text { Unrelated } & & 494 & 0.5 & & 487 & 1.4 \\ \text { Priming } & 20 & 0.2 & & 1 & 0.4 & \end{array}$

\section{DISCUSSION OF EXPERIMENTS 3, 4, AND 5}

In Experiments 3 and 4 we investigated whether a priming effect for perceptually related word pairs could be found after activation of perceptual information of the individual words. Prior to the priming task we presented decision tasks that were intended to activate this perceptual information. In lexical decision (Experiment 3) there was still no priming effect for perceptually related word pairs, but in pronunciation (Experiment 4) there was. The presence of perceptual priming in pronunciation suggests that prior activation of perceptual features of a word makes those features more available on subsequent presentations and this may have led to priming effects for perceptually related words. However, an alternative interpretation was that the perceptual priming effect was somehow caused by repetition effects. This was tested in Experiment 5. We obtained no priming for 
perceptually related pairs in Experiment 5. Therefore, the presence of priming for perceptually related pairs in Experiment 4 cannot be ascribed to the mere presentation of the target stimuli prior to the pronunciation task. Instead, the absence of priming in Experiment 5 shows that in order for such a priming effect to occur it is necessary to give a task in which perceptual information is activated. This is an interesting finding that suggests that the experimental context influences what features of a word will be retrieved.

A somewhat problematic aspect of the data, however, is that no perceptual priming was obtained in Experiment 3, which used a lexical decision task. A possible reason for the different results obtained with lexical decision and pronunciation is that the priming effect for perceptually related pairs was masked by relatedness checking strategies in the lexical decision task. Relatedness checking results in facilitation for word pairs that have an obvious relation, and in inhibition for word pairs that are considered unrelated by the participant. Because most participants do not notice the perceptual relation between the perceptually related word pairs these are considered unrelated. The same explanation has been used to explain the absence of priming effects for mediated prime target pairs in lexical decision (Balota \& Lorch, 1986; de Groot, 1983; McNamara \& Altarriba, 1988).

Balota and Lorch studied priming for mediated pairs (e.g., lion-[tiger]-stripes) in both lexical decision and pronunciation. They obtained priming for mediated pairs in pronunciation but not in lexical decision. They argued that a relatedness checking strategy masked the priming effect for mediated pairs in lexical decision. Because participants did not notice the relation between prime (e.g., lion) and target (e.g., stripes) the mediated word pairs were considered unrelated. As a result, responses to mediated targets were inhibited by relatedness checking. Balota and Lorch further argued that in the pronunciation task mediated priming effects occur because participants do not engage in relatedness checking in this task. The arguments of Balota and Lorch may also apply to words that have a perceptual relation. Participants do not notice this perceptual relation and therefore relatedness checking processes may mask the priming effect in lexical decision. The fact that only an occasional participant had noticed the perceptual relation between prime-target pairs is consistent with this hypothesis. In the pronunciation task relatedness checking does not play a role. This may explain why we found perceptual priming in Experiment 4 but not in Experiment 3.

Experiment 6 further investigated whether the absence of priming in lexical decision in Experiment 3 was indeed due to relatedness checking strategies. The experiment was designed to minimize the influence of relatedness checking strategies. Previous research with the lexical decision task (McNamara \& Altarriba, 1988) suggests that the presence of associatively related word pairs may encourage participants to use relatedness checking strategies. McNamara and Altarriba (Experiment 1) obtained a mediated priming effect in lexical decision when associatively related pairs were absent but not when associatively related pairs were present. They argued that the inclusion of associatively related pairs may have led participants to use relatedness checking strategies and that these strategies masked the priming effect for mediated pairs. They assumed that not including associates in the stimulus list would eliminate the use of relatedness checking strategies. Thus, if the absence of perceptual priming in lexical decision in Experiment 3 was indeed due to relatedness checking processes, perceptual priming should be obtained if associatively related pairs are eliminated from the experiment. We tested this in Experiment 6. We first presented the words from the perceptually related pairs in the two perceptual activation tasks. Then we tested priming for the perceptually related word pairs in lexical decision. The stimulus list contained no word pairs with an associative relation. 


\section{EXPERIMENT 6}

\section{Method}

Participants. Thirty-eight students of the University of Amsterdam participated in the experiment. They received course credit or a small monetary fee for their participation.

Procedure and Materials. The same prime and target stimuli were used as in Experiment 3, with the exception that all associatively related word pairs were recombined to form unrelated word pairs. Thus, no associatively related pairs were presented. All other aspects of the procedure were identical to those of Experiment 3. Thus, prior to the lexical decision task two activation tasks were given in which a decision about perceptual features had to be made.

Results

Mean reaction times and error rates are given in Table 5. Only correct response times shorter than $1000 \mathrm{~ms}$ were included in the analyses. This resulted in exclusion of $0.8 \%$ of the reaction times. Mean lexical decision latencies were $16 \mathrm{~ms}$ faster for perceptually related pairs than for perceptually unrelated pairs, $t(37)=2.22, p<.05 .3$ Thus, as expected we did obtain a significant perceptual priming effect in a lexical decision task. An analysis on the errors revealed no significant effect of relatedness, $t(37)=0.65, p=.52$. Two of the 38 participants noticed the perceptual relation of some of the word pairs.

Table 5. Mean Response Times (in milliseconds) and Percentage Errors for Experiment 6.

\section{Perceptual pairs}

RT PE

Exp. 6: Lexical Decision

$\begin{array}{lrll}\text { Related } & 541 & 3.4 & \\ \text { Unrelated } & & 557 & 4.0 \\ \text { Priming } & 16 & 0.6 & \end{array}$

Note: no associatively related prime-target pairs were presented in Experiment 6.

\section{Discussion}

In the present experiment associatively related prime-target pairs were excluded from the stimulus list and a significant perceptual priming effect was obtained, showing that priming for perceptually related words can be obtained in a lexical decision task. These results show that the absence of priming for perceptually related prime-target pairs in Experiment 3 was due to the inclusion of associatively related prime-targets pairs. 
McNamara and Altarriba (1988) obtained a mediated priming effect in lexical decision when associatively related pairs were absent but not when these were present in the experiment. They argued that the inclusion of associatively related pairs may have led participants to use relatedness checking strategies and that these strategies masked the priming effect for mediated pairs. Similarly, perceptual priming effects may have been masked by relatedness checking strategies in Experiment 3 that included associatively related pairs, but not in the present experiment that excluded associatively related pairs. Thus, our findings are entirely consistent with the pattern of results obtained by other researchers using mediated pairs and with the interpretation that in lexical decision perceptual priming effects, like mediated priming effects, may be masked by relatedness checking strategies. In summary, the results of the present experiment clearly show that perceptual priming in lexical decision can be obtained after perceptual activation tasks when the experiment is designed in such a way that relatedness checking strategies are eliminated.

\section{GENERAL DISCUSSION}

In the present series of experiments we investigated whether a priming effect can be found for word pairs such as pizza-coin that refer to objects that are similar in shape. We tried to replicate the perceptual priming effects that have been found by Schreuder et al. (1984) and Flores d'Arcais et al. (1985). Our results show that in neither lexical decision nor in pronunciation was there priming for perceptually related word pairs, while there was significant priming for associates in all experiments. Only under very specific conditions was a priming effect for perceptually related word pairs found. This was shown in Experiment 4 (pronunciation) and Experiment 6 (lexical decision). In these experiments prior to the priming task the words were presented in activation tasks that asked the participants to make decisions about perceptual features of the words' referents. Small, but reliable, priming effects were found for the perceptually related word pairs. In none of the other experiments was priming for perceptually related word pairs obtained. One might argue that the absence of perceptual priming in Experiment 1 (lexical decision) was due to relatedness checking strategies like in Experiment 3. Although we argued that perceptual priming effects can be masked by relatedness checking strategies, it is unlikely that this was the reason we did not obtain perceptual priming in Experiment 1. In Experiment 2 we investigated perceptual priming in pronunciation task. All other aspects of the procedure were identical to that of Experiment 1. If perceptual priming had been masked by strategies in Experiment 1, we would have obtained the effect in Experiment 2, because pronunciation is not sensitive to relatedness checking strategies. However, no perceptual priming occurred in Experiment 2. Furthermore, perceptual priming was also absent in Experiment 5 in which we also used a pronunciation task. Thus, we can safely conclude that under standard conditions no priming for perceptually related word pairs is obtained.

The first interesting finding of the present study is the absence of a priming effect for perceptually related word pairs under normal conditions. Such an effect was obtained in earlier studies by Schreuder et al. (1984) and Flores d'Arcais et al. (1985). Their results have been referred to often in the literature as evidence of semantic priming without association (Chiarello, Burgess, Richards \& Pollock, 1990; Moss, Ostrin, Tyler, \& Marslen-Wilson, 1995; Neely, 1991; Shelton \& Martin, 1992; Williams, 1996). A priming effect for perceptually related word pairs would be particularly interesting, because it would show that words are activated by concepts with which they have no direct or mediated association. However, as we pointed out in the introduction, there were some 
methodological problems with the Schreuder et al. and Flores d'Arcais et al. studies, so that interpretation of their findings was complicated. Therefore, a replication under less problematic conditions was needed. We showed that under better controlled conditions no priming is obtained for perceptually related word pairs.

Our results are consistent with the claim that previous findings of nonassociative semantic priming are not supported by automatic activation processes. As was argued by Shelton and Martin (1992), priming for semantic only pairs in lexical decision may have been the result of relatedness checking strategies. Although these relatedness checking strategies are not assumed to play a role in the pronunciation task, nonassociative semantic priming effects in pronunciation may also not reflect automatic processes. Instead, the effect that was found by Seidenberg et al. (1984) and in some of Lupker's (1984) experiments may be due to expectancy based strategies. Another problem is that some of the observed nonassociative semantic priming effects might in fact be mediated priming effects. Semantic relatedness is usually defined as shared category membership, therefore both members might be directly associated to the category name. Thus, the possibility that there are mediated associations between prime and target cannot be ruled out. Moreover, priming effects for semantic only (but possibly mediated) pairs in pronunciation have been very small. For example, Lupker found $7 \mathrm{~ms}$ priming, and Seidenberg et al. found $11 \mathrm{~ms}$ priming for semantic only pairs. In the light of these small effects the finding of a 23 ms perceptual priming effect by Schreuder is all the more surprising. However, as we showed in the present study, these results do not replicate when procedures are used that do not suffer from the methodological problems of the Schreuder et al. (1984) study.

Another interesting finding of our study was that we obtained priming for perceptually related word pairs when prior to the pronunciation task participants made judgments about the perceptual properties of the words' referents. This finding suggests that the global experimental context influences priming effects. The importance of context on priming has also been shown in other studies. McKoon and Ratcliff (1995) showed that priming effects can be greatly reduced or even eliminated if the type of relation of an associated word pair differs from the type of relation of the other associates in the list context. For example, priming for the word pair close-near was obtained only if the pair appeared in a list of synonym pairs (e.g., quick-fast, broad-wide) and not if it appeared in a list of opposite pairs (e.g., quick-slow, broad-narrow). McKoon and Ratcliff argued that these results were not caused by strategies since they were obtained at a short SOA in both lexical decision and pronunciation. A study by Conrad (1978) also showed that context can influence priming effects. She observed that priming effects for semantic properties were larger if these properties were appropriate in the context. For example after the sentence The man tuned the piano there was more priming for the word string, whereas after the sentence The man lifted the piano there was more priming for the word heavy.

These results and those of our study all suggest that automatic priming effects depend on the features of words that are activated. These features may depend on the other word pairs in the test list or on the task that participants perform just prior to the priming task. Spreading activation interpretations of associative priming have often, for the sake of simplicity, assumed that associates are connected at the word level. However, in the model proposed by Collins and Loftus (1975) words are connected via the features they have in common. The more features they have in common, the more closely they are related. Thus, associations between words are the result of overlap at a feature level. It is often assumed that features of concepts differ in importance or accessibility (Barsalou, 1993). Normally, priming effects would be the result of overlap between the most accessible, or 'core' 
features of two concepts. But this accessibility is variable, and can be changed by the context in which words appear (Peterson \& Simpson, 1989) and by recent experiences with words. Thus, if some features are highly relevant in a specific context, they have a high probability of being activated, even if their accessibility under normal conditions is low. Additionally, features that normally have low accessibility can become highly accessible as the result of recent activation.

Our results showed that, under 'normal' conditions, overlap of perceptual features between concepts does not lead to priming between these concepts. The contexts of the lexical decision and pronunciation tasks do not lead to automatic activation of these features. However, the activation tasks of Experiments 3, 4, and 6 were aimed at activation of perceptual features. Thus, the contexts of these activation tasks lead to a higher accessibility of perceptual features. Because features that have recently been activated have a higher accessibility, they have a higher probability of being activated again in the priming task. If perceptual features are activated, then overlap between perceptual features of two concepts will lead to a priming effect.

With this framework we can speculate why Schreuder et al. did obtain priming for perceptually related word pairs. Two aspects of their experiments may be important. The first is that each target was presented four times, once in each condition (perceptually related, conceptually related, both perceptually and conceptually related, and unrelated). Thus, each target was twice presented in a condition in which there was a perceptual relation between prime and target. The second aspect that may be important is that the prime remained on the computer screen when the target was presented. This presentation procedure may have focused attention on the relation between the prime and target. In two of the four conditions this relation involved overlap of perceptual features. On the first presentation of the target in the perceptual condition this may have led to activation of some perceptual features. The next time a target was presented, some of the perceptual features may have been more accessible due to this recent activation. This higher accessibility of perceptual features would then have led to priming for word pairs that have overlap of perceptual features. This account for the difference between our results and those of Schreuder et al. is of course speculative. However, it should be noted that the results of Schreuder et al. should be interpreted with caution because the materials were confounded with experimental conditions.

The spreading activation model is not specific enough to predict exactly under which conditions priming is found for perceptually related word pairs. More generally, spreading activation models do not specify which features are activated when a word is processed, or how feature overlap is exactly related to priming effects. At any rate, an important conclusion from this discussion is that word associations cannot solely be viewed as static connections between two words. It seems more realistic to view an association as a context dependent degree of featural overlap between two words. Thus, it is not the degree of overlap between all features of concepts that determines the strength of an association, but the degree of overlap between activated features of concepts. Both the present context and recent experiences with a concept affect which features are activated.

To summarize, our study shows that priming for perceptually related words does not occur under standard conditions. The absence of priming for perceptually related words is consistent with the absence of nonassociative semantic priming in other studies that were designed to minimize the influence of strategies. Perceptual priming is obtained only when the activation of perceptual properties of words is required by a task performed just prior to 
Perceptual Priming 19

the priming task. This result shows that what features of a word are activated is not static but instead can be dynamically affected by the context in which a word occurs. 


\section{REFERENCES}

ANDERSON, J. R. (1983). A spreading activation theory of memory. Journal of Verbal Learning and Verbal Behavior, 22, 261-295.

BALOTA, D. A., \& LORCH, R. F. (1986). Depth of automatic spreading activation: Mediated priming effects in pronunciation but not in lexical decision. Journal of Experimental Psychology: Learning, Memory, and Cognition, 12, 336-345.

BARSALOU, L. W. (1993). Flexibility, structure, and linguistic vagary in concepts: manifestations of a compositional system of perceptual symbols. In A. F. Collins, S. E. Gathercole, M. A. Conway, \& P. E. Morris (Eds.) Theories of memory. Hove, United Kingdom: Lawrence Erlbaum.

BECKER, C. A. (1980). Semantic context effects in visual word recognition: An analysis of semantic strategies. Memory \& Cognition, 8, 493-512.

Chiarello, C., Burgess, C., Richards, L., \& Pollock, A. (1990). Semantic and associative priming in the cerebral hemispheres: Some words do, some words don't...sometimes, some places. Brain and Language, 38, 75-104.

Collins, A. M., \& LofTUS, E. F. (1975). A spreading-activation theory of semantic processing. Psychological Review, 82, 407-428.

CONRAD, C. (1978). Some factors involved in the recognition of words. In J. W. Cotton \& R. L. Klatzky, Semantic factors in cognition. Hillsdale, NJ: Lawrence Erlbaum. DE GROOT, A. M. B. (1980). Mondelinge Woordassociatienormen: 100 woordassociaties op 460 Nederlandse zelfstandige naamwoorden. [Verbal Word Association Norms: 100 Word Associations to 460 Dutch Nouns]. Lisse, The Netherlands: Swets \& Zeitlinger.

DE GROOT, A. M. B. (1983). The range of automatic spreading activation in word priming. Journal of Verbal Learning and Verbal Behavior, 22, 417-436.

DE GROOT, A. M. B. (1985). Word context effects in naming and lexical decision. Quarterly Journal of Experimental Psychology, 37A, 281-297.

DEN HEYER, K., BRIAND, K., \& DANNENBRING, G. L. (1983). Strategic factors in a lexical decision task: Evidence for automatic and attention-driven processes. Memory \& Cognition, 11, 374-381.

FISCHLER, I. (1977). Semantic facilitation without association in a lexical decision task. Memory \& Cognition, 5, 335-339.

FLORES D'ARCAIS, G. B., SCHREUDER, R., \& GlAZENBORG, G. (1985). Semantic activation during recognition of referential words. Psychological Research, 47, 39-49.

LAUTESLAGER, M., SCHAAP, T., \& SCHIEVElS, D. (1986). Schriftelijke woordassociatienormen voor 549 Nederlandse zelfstandige naamwoorden. [Written Word Association Norms for 549 Dutch Nouns]. Lisse, The Netherlands: Swets \& Zeitlinger.

LUND, K., BURGESS, C., \& ATChLEY, R. A. (1995). Semantic and associative priming in high-dimensional semantic space. Proceedings of the Cognitive Science Society (pp. 660-665). Hillsdale, NJ.: Erlbaum Publishers.

LUPKER, S. J. (1984). Semantic priming without association: A second look. Journal of Verbal Learning and Verbal Behavior, 23, 709-733.

MASSON, M. E. J. (1995). A distributed memory model of semantic priming. Journal of Experimental Psychology: Learning, Memory, and Cognition, 21, 3-23.

MCKOON, G. \& RATCLIFF, R. (1992). Spreading activation versus compound cue accounts of priming: Mediated priming revisited. Journal of Experimental Psychology: Learning, Memory, and Cognition, 18, 1155-1172. 
MCKoON, G., \& RATCLIFF, R. (1995). Conceptual combinations and relational contexts in free association and in priming in lexical decision and naming. Psychonomic Bulletin \& Review, 2(4), 527-533.

MCNAmARA, T. P. (1992). Theories of priming: I. Associative distance and lag. Journal of Experimental Psychology: Learning, Memory, and Cognition, 18, 11731190.

MCNAMARA, T. P. (1994). Theories of priming: II. Types of primes. Journal of Experimental Psychology: Learning, Memory, and Cognition, 20, 507-520.

MCNAMARA, T. P., \& AlTARRIBA, J. (1988). Depth of spreading activation revisited: Semantic mediated priming occurs in lexical decisions. Journal of Memory and Language, 27, 545-559.

MEYER, D. E., \& SCHVANEVELDT, R. W. (1971). Facilitation in recognizing pairs of words: Evidence of a dependence between retrieval operations. Journal of Experimental Psychology, 90, 227-234.

Moss, H. E., OSTRIN, R. K., TYLER, L. K., \& MARSLEN-WILSON, W. D. (1995). Accessing different types of lexical semantic information: Evidence from priming. Journal of Experimental Psychology: Learning, Memory, and Cognition, 21, 1-21.

NEELY, J. H. (1977). Semantic priming and retrieval from lexical memory: Roles of inhibitionless spreading activation and limited-capacity attention. Journal of Experimental Psychology: General, 106, 226-254.

NEELY, J. H. (1991). Semantic priming effects in visual word recognition: A selective review of current findings and theories. In D. Besner \& G. W. Humphreys (Eds.), Basic processes in reading: Visual word recognition. (p 264-336). Hillsdale, NJ: Erlbaum.

PETERSON, R. R., \& SiMPSON, G. B. (1989). Effect of backward priming on word recognition in single-word and sentence contexts. Journal of Experimental Psychology: Learning, Memory, and Cognition, 15, 1020-1032.

POSNER, M. I., \& SNYDER, C. R. R. (1975). Attention and cognitive control. In R. L. Solso (Ed.), Information processing and cognition: The Loyola symposium (pp. 5585). Hillsdale, NJ: Lawrence Erlbaum Associates.

RAAIJMAKERS, J.G.W., SCHRIJNEMAKERS, J.M.C., \& GREMMEN, F. (1997) How to deal with the "language-as-a-fixed-effect fallacy": Common misconceptions and alternative solutions. Manuscript submitted for publication.

RATCLIFF, R., \& MCKOON, G. (1988). A retrieval theory of priming in memory. Psychological Review, 95, 385-408.

SCHREUDER, R., FLORES D'ARCAIS, G. B., \& GLAZENBORG, G. (1984). Effects of perceptual and conceptual similarity in semantic priming. Psychological Research, 45, 339-354.

SEIDENBERG, M. S., WATERS, G. S., SANDERs, M., \& LANGER, P. (1984). Preand postlexical loci of contextual effects on word recognition. Memory \& Cognition, 12, 315-328.

SHELTON, J. R., \& MARTIN, R. C. (1992). How semantic is automatic semantic priming? Journal of Experimental Psychology: Learning, Memory, and Cognition, 18, 1191-1210.

VAN DER MADE-VAN BEKKUM, I. J. (1973). Nederlandse woordassociatienormen. [Dutch Word Association Norms]. Amsterdam: Swets \& Zeitlinger. 
VAN LOON-VERVOORN, W. A., \& VAN BEKKUM, I. J. (1991). Woordassociatie lexicon. [Word Association Lexicon]. Amsterdam/Lisse: Swets \& Zeitlinger.

WILLIAMS, J. N. (1996). Is automatic priming semantic? European Journal of Cognitive Psychology, 8, 113-161.

ZEELENBERG, R., PECHER, D., DE KoK, D., \& RAAIJMAKERS, J. G. W. (in press). Inhibition from nonword primes in lexical decision re-examined: The critical influence of instructions. Journal of Experimental Psychology: Learning, Memory, and Cognition. 


\section{Appendix}

Stimuli used in Experiments 1 to 6.

Perceptually related pairs (newly created)

Dutch

$\begin{array}{ll}\text { Prime } & \text { Target } \\ \text { kom } & \text { helm } \\ \text { munt } & \text { pizza } \\ \text { reep } & \text { plank } \\ \text { trap } & \text { tribune } \\ \text { lijm } & \text { honing } \\ \text { wiel } & \text { taart } \\ \text { slang } & \text { rivier } \\ \text { kegel } & \text { fles } \\ \text { kluis } & \text { oven } \\ \text { koffie } & \text { inkt } \\ \text { armband } & \text { hoepel } \\ \text { amandel } & \text { oog } \\ \text { borstel } & \text { egel } \\ \text { pistool } & \text { boor } \\ \text { oorring } & \text { reddingsboei } \\ \text { vuurwerk } & \text { fontein } \\ \text { batterij } & \text { kurk } \\ \text { verkeersbord } & \text { lollie }\end{array}$

\section{English*}

Prime Target

$\begin{array}{ll}\text { bowl } & \text { helmet } \\ \text { coin } & \text { pizza } \\ \text { (candy) bar } & \text { board } \\ \text { stairs } & \text { gallery } \\ \text { glue } & \text { honey } \\ \text { wheel } & \text { cake } \\ \text { snake } & \text { river } \\ \text { skittle } & \text { bottle } \\ \text { safe } & \text { oven } \\ \text { coffee } & \text { ink } \\ \text { bangle } & \text { hoop } \\ \text { almond eye } & \\ \text { brush } & \text { hedgehog } \\ \text { pistol } & \text { drill } \\ \text { earring } & \text { life saver } \\ \text { fire-works } & \text { fountain } \\ \text { battery } & \text { cork } \\ \text { traffic-sign } & \text { lollipop }\end{array}$

Perceptually related pairs from Schreuder, Flores d'Arcais and Glazenborg (1984).

\begin{tabular}{llll} 
Prime & Target & Prime & Target \\
dolk & beitel & dagger & chisel \\
hoed & pudding & hat & pudding \\
pijp & saxofoon & pipe & saxophone \\
naald & degen & needle & foil \\
kompas & klok & compass & clock \\
penseel wortel & \multicolumn{2}{l}{ paintbrush carrot } & \\
spijker & potlood & nail & pencil \\
trommel & vuilnisvat & drum & garbage can \\
punaise tuintafel l drawing pin & garden table & \\
zeppelin & haai & zeppelin & shark \\
televisie & fornuis & television & stove \\
stokbrood & vinger & french bread & finger \\
wasknijper & nietmachine & clothespin & stapler \\
sinaasappel & bal & orange & ball \\
scheerkwast & fakkel & shaving brush & torch
\end{tabular}


$\begin{array}{ll}\text { broodrooster } & \text { kast } \\ \text { tennisracket } & \text { banjo } \\ \text { injectiespuit } & \text { dobber }\end{array}$

Associated pairs

\begin{tabular}{|c|c|c|c|c|}
\hline Prime & Target & & Prime & Target \\
\hline $\operatorname{man}$ & vrouw & & $\operatorname{man}$ & woman \\
\hline kameraad & vriend & & comrade & friend \\
\hline vlug & snel & & quick & fast \\
\hline vader & moeder & father & mother & \\
\hline goor & vies & & dingy & dirty \\
\hline zilver & goud & & silver & gold \\
\hline neef & nicht & & cousin(male) & cousin(female) \\
\hline haas & konijn & & hare & rabbit \\
\hline begin & einde & & start & end \\
\hline veulen & paard & & foal & horse \\
\hline oom & tante & & uncle & aunt \\
\hline zoon & dochter & son & daught & \\
\hline kei & steen & & boulder stone & \\
\hline peper & zout & & pepper & salt \\
\hline binnen & buiten & & inside & outside \\
\hline fraai & mooi & & pretty & beautiful \\
\hline duit & geld & & farthing money & \\
\hline raar & vreemd & odd & strange & \\
\hline kil & koud & & chilly & cold \\
\hline woning huis & & dwellin & house & \\
\hline opa & oma & & grandfather & grandmother \\
\hline ree & hert & & roe & deer \\
\hline zwijn & varken & & pig & boar \\
\hline kalf & koe & & calf & cow \\
\hline
\end{tabular}

$\begin{array}{ll}\text { toaster } & \text { cupboard } \\ \text { tennis racket } & \text { banjo } \\ \text { syringe } & \text { float }\end{array}$




\section{Author Note}

We would like to thank Lael Schooler for his help in constructing stimulus materials and Dirk de Kok for his help in collecting the relatedness ratings. We would also like to thank Annette de Groot and Rob Schreuder for useful suggestions on an earlier draft of this manuscript.

Correspondence concerning this article should be addressed to Diane Pecher or René Zeelenberg who are both at the Department of Psychonomics, Roetersstraat 15, 1018 WB, The Netherlands. Electronic mail may be sent to Diane Pecher: pn_pecher@macmail.psy.uva.nl or René Zeelenberg: pn_zeelenberg@macmail.psy.uva.nl.

\section{Footnotes}

1 Note that the words themselves are not perceptually similar.

2 Separate analyses of the data for the word pairs taken from Schreuder et al. (1984) and for the newly created word pairs were performed for this and all subsequent experiments. In all experiments the results were the same for the Schreuder et al. word pairs and for the newly created set of word pairs.

3 For all experiments we report only results from subject analyses of the data. Item based analyses would not be appropriate because in the present series of experiments the variance due to items is controlled for by counterbalancing. Elsewhere we have argued in more detail (Raaijmakers, Schrijnemakers, \& Gremmen, submitted) that item based analyses are not necessary when items are counterbalanced across conditions. However, for those readers who do not trust these arguments we did perform item based analyses. In both Experiment 4 and 6 these analyses showed significant perceptual priming effects, $t(35)$ $=2.47, \mathrm{p}=.02$ and $\mathrm{t}(35)=2.08, \mathrm{p}=.04$, respectively. 